Journal Article

\title{
Assessing learning in the early years' outdoor classroom: examining challenges in practice
}

Davies, R. and Hamilton, P.

This article is published by Taylor \& Francis. The definitive version of this article is available at:

http://www.tandfonline.com/doi/abs/10.1080/03004279.2016.1194448

\section{Recommended citation:}

Davies, R. and Hamilton, P. (2016), 'Assessing learning in the early years' outdoor classroom: examining challenges in practice, ' Education 3-13: International Journal of Primary, Elementary and Early Years Education, Vol. 20, No.10, 1-13, published on line, doi: 10.1080/03004279.2016.1194448 
Assessing learning in the early years' outdoor classroom: examining challenges in practice.

\title{
Ruth Davies and Paula Hamilton
}

School of Social and Life Sciences, Glyndŵr University, Mold Road, Wrexham, LL11 2AW, UK. [Email: r.davies@glyndwr.ac.uk (01978 293108) p.hamilton@glyndwr.ac.uk (01978 293332)].

\begin{abstract}
The benefit the outdoor environment has for young children's development is widely documented. However, there is less literature outlining practitioners' experiences of assessing learning in the outdoors and factors which impact the level and quality of assessments undertaken. This study, based on a pragmatic mixed methods approach, undertaken in 9 early years' settings in North Wales, reports the findings of 37 practitioners. The research suggests that assessing children in the outdoors is not used to its potential. Factors impeding the use of the outdoor classroom include: lack of appropriate resources; level of staff expertise; child-staff ratio; adverse weather; and changes to curriculum policy which place emphasis on the formal assessment of children. There appears to be assumptions about learners most likely to benefit from outdoor learning and assessment: boys; children in socio-economically deprived areas; and children with additional learning needs. The paper highlights the need for broader training opportunities for practitioners on planning for learning and assessment in the outdoors that go beyond a single course focus. With creative planning, there is no reason why summative assessments of all areas of learning within the early years' curriculum, cannot be done as effectively outdoors as they may be being done indoors.
\end{abstract}

Key words: assessing outdoors; early years; outdoor learning

\section{Introduction}

Outdoor learning is not a new perspective; there have been many scholars who have endorsed the benefits of children having experiences of this natural learning environment over the centuries (e.g. Comenius, Rousseau, Pestalozzi, Froebel, Steiner, Isaccs; the McMillan sisters). Some argue the benefits to learning and development are so significant that an indoor based education alone is not sufficient to fully educate children (Waite 2011). The outdoor environment has much potential for promoting children's cognitive and physical development (Waite and Davis 2007; Storli and Hagen 2010); communication, social and emotional development (Knight 2009; Eloquin and Hutchinson 2011); socio-cultural identity (Aasen et al. 2009); levels of concentration and motivation to learn (O’Brien 2009; Eloquin and Hutchinson 2011); and children are more likely to initiate interaction and engage in shared thinking and questioning (Waters 2013). However, it is not the intention of this paper to explore the benefits of outdoor learning. Rather the gap in the literature is associated with understanding practitioners' experiences of assessing children's learning in the outdoors and factors which might impact the level and quality of assessments undertaken.

The benefits of the natural learning environment to children's development has influenced early years' curriculum policy and pedagogy in many countries, most notably Scandinavian countries such as Denmark, Finland and Norway (Knight 2009; Lee-Hammond and Waller 2014). It is argued that Finland's constant success in the Programme for International Student Assessment can partly be attributed to the importance placed on outdoor learning and the way Finnish practitioners develop positive relationships and support children in their play and early learning experiences, which motivates children and leads to successful learning throughout their school career (May et al 2006; Hännikäinen and Rasku-Puttonen 2010). Over the last decade, outdoor learning in the United Kingdom [U.K.], has enjoyed a revival. Curriculum policies related to the early years in Wales (Department for Children, Education, Lifelong Learning and Skills [DCELLS] 2009) and Scotland (Learning and Teaching Scotland 2010), encourage utilisation of the outdoor environment. The initial intention of the Foundation Phase for Wales (a curriculum for children aged 3-7 years) was for a curriculum not to be driven by assessment but by active learning, play and experiential learning, with a strong emphasis on the use of the outdoors (DCELLS 2008). During the piloting phase of the Foundation Phase, in the early 2000s, it became apparent that many settings did not have access to suitable outdoor areas (SirajBlatchford et al. 2006) and practitioners did not exploit the learning opportunities their outdoor environment afforded (Maynard and Waters 2007). In 2011, Estyn (an independent body that inspects quality and standards in education and training in Wales) acknowledged how many practitioners make better use of the outdoor environment but do not use it enough to develop children's reading and writing, 
Welsh language, creativity, or information and communication technology [ICT] and are less likely to undertake assessments of children's learning in the outdoors. More recently, early years' practitioners are facing increasing pressure to 'teach' children in order to improve attainment scores. The introduction of the National Literacy and Numeracy Framework [LNF] into the Foundation Phase in 2013, for children aged 5 to 7 years old, has placed an increasing obligation on practitioners to formally assess children (Organisation for Economic Co-operation and Development 2014; Donaldson 2015). Such pressure may explain why whole group, adult initiated indoor teaching, is more frequently observed in settings than child initiated learning; an approach which increases as children progress through the Foundation Phase (Waldron et al. 2014a ; Waldon et al. 2014b).

The testing or assessment of primary school children is extremely controversial and is perhaps one of the most contentious activities that teachers engage in (Muijs and Reynolds 2011). State systems exacerbate this trend, with teaching often geared towards preparation for mandated tests in a quest to drive up standards of education, holding schools accountable, to ensure that the U.K. remains economically competitive (Muijs and Reynolds 2011; Allsopp 2014). The requirements of early learning outcomes/goals in Wales and England has promoted on-going debates among practitioners, with many concerned about the resultant pressures on young children. (Johnson 2014). Although assessment can be a useful tool that helps raise standards of care and education for young learners, there remains for many, significant reservations about its formality and the focus on educational achievement. (Johnson 2014). The Tickell Review (2011), an English based report which responded to practitioners' concerns over the bureaucratic paperwork associated with assessment, recommended that practitioners document only key achievements that are necessary to promote successful learning and development. Unfortunately, continuous pressure on teachers to raise attainment scores frequently leads to practitioners who are so preoccupied with assessment (Basford and Bath 2014) that they are reluctant to relinquish their control of children's learning (Maynard and Chicken 2010), instead imposing rigid structure and restrictions, which may result in less utilisation of the outdoors (Waite and Pratt 2011).

In addition to changes to curriculum policy, which may work against opportunities for outdoor learning and assessment, early years' practitioners may have their own personal perceptions regarding play, experiential learning and use of the outdoors. Practitioners who have an authoritarian attitude may constrain learning (Humberstone and Stan 2011), as they may be less likely to adopt a pedagogy that recognises learning from a child's viewpoint (McInnes et al. 2013) and to see the value that the outdoor environment has in enabling children to reach higher levels of cognitive understanding (Fägerstam and Samuelsson 2014). Some practitioners have been found to hold assumptions regarding the groups of children who most benefit from outdoor learning. The low expectations typically attached to boys, especially those from lower socio-economic groups, often sees them as being particularly suited to outdoor learning (Estyn 2011; Bradbury 2014). However, care should be taken as the evidence to suggest that learning preferences, including those for the outdoors, are gender specific is not conclusive (Bartlett and Burton 2016; Thompson 2011). Even practitioners, who recognise the value of introducing risk-taking as a strategy for promoting confident and able learners (Elliott 2014), might be reticent to do so. Resistance may be due to health and safety regulations (Little et al. 2011); a fear of litigation (Bundy et al. 2009); whether children are viewed as being competent (Waller et al. 2010); or a lack of confidence in a practitioner's own ability to utilise the outdoor environment (Knight 2011). Wragg (2013) asserts even when evidence is presented to practitioners, of the value of risk, some find it difficult to adjust internalised attitudes, beliefs and practice.

Knight (2011) and Glazzard (2014) argue that the training most likely to be effective in achieving higher levels of engagement and improved outcomes for learners, is that which helps practitioners to recognise their role as a facilitator who bases learning and assessment around children's interests in the natural environment. Unfortunately, a lack of specialised training in Wales for practitioners, including senior management, has led to ineffective outdoor learning environments, where adults take a structured supervisory rather than educative role (Estyn 2011). Groves and McNish (2011) claim when practitioners have undertaken training and begin to spend more time outdoors, there is often a positive change in their attitude, which can lead to improved interactions and a better understanding of their learners.

The Curriculum for Wales is under review (Donaldson 2015). In the responses to the Consultation document (Department for Education and Skills [DfES] 2014), concern has been expressed that some of the assessment arrangements that have been introduced are contrary to the ethos 
of the Foundation Phase and emphasis on the NLF will result in reduced utilisation of the outdoor classroom, including opportunities provided to children aged 3-5 years. The purpose of this paper is to outline some of the experiences and concerns of early years' practitioners in Wales with regards to providing opportunities for children's learning and assessment in the outdoors. It is part of a longitudinal study which aims to monitor the impact that revisions made to the Welsh early years curriculum have on the utilisation of the outdoor classroom.

\section{Methods}

The study, which drew upon an interpretive-deductive paradigm, was conducted during the spring term of 2015. Using a pragmatic mixed methods approach of inquiry, the research design consisted of both qualitative and quantitative data, and utilised a questionnaire and semi-structured interviews. The study focused on 9 early years English medium settings, located in North East Wales. One setting's provision was for children aged 2 to 4 years of age, while all others provided an education for children aged 3 to 11 years of age. According to Estyn, 5 of the 9 settings were considered to neither be advantaged or disadvantaged; 2 settings mostly advantaged; and 2 settings socially and economically disadvantaged. The children were from predominantly English speaking homes.

Out of a total of 50 questionnaires distributed to 10 early years' settings, (settings which one of the researchers had an established relationship with through her role as a university liaison tutor for undergraduate students on work experience), 37 were returned from 9 of the settings, resulting in a $74 \%$ response rate. 5 questionnaires had been sent to each setting; the head teacher was asked to distribute these among staff working within the Foundation Phase. Questionnaires were completed by 1 head teacher, 3 deputy head teachers, 14 teachers and 19 teaching assistants. The length of experience practitioners had in working with children in the Foundation Phase varied from 3 months to 40 years, with a mean of 12.7 years' experience. 22 participants worked with nursery/ reception children (3-5 year olds), 9 participants worked with Year One and Year Two children (5-7 year olds) and 6 participants worked in a mixed-age Foundation Phase setting (3-7 year olds). The self-completed questionnaire, which consisted of both closed and open questions, included: Which areas of learning of the Foundation Phase do you assess outdoors and how frequently are these assessed? Does anything prevent you from assessing children's learning in the outdoors? What factors make assessing in the outdoors most effective? Where do you carry out the majority of assessments? What methods of assessment do you use when assessing outdoors? What training have you undertaken in the use of the outdoor environment?

Participants completing the questionnaire were invited to partake in a follow-up interview. Out of the 14 participants who agreed to be interviewed, 10 were chosen at random. These participants, a head teacher; a deputy head teacher; 4 teachers and; 4 teaching assistants, were all female. The semistructured interview schedule, which was based on data collected from the questionnaires, allowed further exploration of key issues and meant different versions of parallel phenomena could be related and analysed to more fully explain the experiences and challenges of assessing young children in the outdoor environment. Additional questions included: Where are most assessments of children's learning carried out? Who undertakes the assessment of children outdoors? Are there any areas of learning, within the Foundation Phase, that are difficult to assess outdoors and if so, why? Are there any current changes or demands to the curriculum that have had an impact on the use of the outdoor classroom for children's learning and assessment? Interviews took place at the participants' workplace, most were digitally recorded and lasted between 30 minutes and 45 minutes. During the interviews, constant checks were made to ensure that what had been written captured the views of the participants. The confidentiality of the settings and school practitioners has been assured through the use of pseudonyms. Before any research was undertaken participants were informed about the purpose of the research, how their responses would be used and they were made aware of their right to withdraw from the study at any time.

Data was analysed using Denscombe's (2010) five stages to inductive analysis. The first stage involved transcribing data into an Excel document; the second stage reading and re-reading data to ascertain emerging key issues/categories; the third stage making comparisons between issues/ categories to determine patterns and relationships; the fourth stage noting isolated and alternative 
perspectives; and finally presenting data in correspondence with the main themes that have emerged and their relation to extant literature.

\section{Findings and discussion}

The following discussion is based on 37 early years' practitioners' experiences of assessing young children's learning in the outdoor environment. Based on such a small sample of practitioners, from 9 settings, the results provided do have limitations, so do not claim to be characteristic of a larger sample. Rather than intending to make generalisations, the study aims to provide an in-depth specific account, which will encourage early years' practitioners, to reflect on the use of the outdoors with regard to children's learning and assessment.

Through critical analysis of data gathered it is clear that all practitioners regarded assessing children in the outdoor environment as having value: 20 participants considered it to be 'extremely valuable', 12 said it was 'valuable' and 5 thought it held 'some value'. Over half of the practitioners ( $n$ 22) believed that the outdoor classroom offered children equally as rich learning and assessment opportunities as those provided within the indoor classroom. None of the 37 practitioners commented there was 'no value' to be had by offering children learning and assessment opportunities in the outdoors. One practitioner (Teaching Assistant 1) stated "You can't run a proper Foundation Phase setting unless you have an outdoor area because you are totally restricting what children can achieve."

Three central themes to have emerged include:

1. 'Who benefits?' The benefits of outdoor learning to children's development is clearly recognised by practitioners, with certain groups of children believed to benefit more than others.

2. 'Assessment: what, where, who, when?' There is a distinction between the nature of curriculum subject areas being assessed outdoors and the role of teachers and that of teaching assistants regarding the location and type of assessments undertaken.

3. 'Factors hindering outdoor assessment' Certain factors exist which make assessing young children in the outdoor environment challenging for practitioners.

\section{Who benefits?}

Although all of the early years practitioners involved in the study agreed that the outdoor classroom had value for all children, nearly half $(n 17)$ expressed that it had more benefits for certain groups of children. Boys were identified as being those most likely to gain from outdoor learning and assessment opportunities.

Boys learn better outdoors, they learn when they are active because their minds learn differently. Also, it suits boys who don't like reading or writing, or being at school. They don't see the outdoors as being in school. They will be learning and not realise it. (Teacher 1)

Boys really like being outside; having freedom to move and to use their big voices on a larger scale. (Deputy Head Teacher)

Children who have additional learning needs, in particular those with language difficulties or delayed social development, were also highlighted as a group best suited to the outdoor classroom.

Children with additional learning needs, who have IEPs [Individual Education Plans], tend to be more independent and less restricted in the outdoor classroom. (Teaching Assistant 1)

It's good for children who are unsteady on their feet, they benefit from the physiotherapy of going out. It's also good for those who are solitary as they start to mix. (Head Teacher)

Children who struggle with language often feel more relaxed from being outdoors. (Teaching Assistant 2)

A further category seen to benefit were children living in socio-economically deprived areas. 
Lively children, who live in flats, particularly benefit from experiencing the outdoors and being allowed to run about. (Teaching Assistant 1)

I used to be negative of the outdoor classroom but seeing the positive impact it can have on our children's outcomes, I now promote it. Many of our children come from really deprived backgrounds. (Teacher 2)

The comments made by these practitioners support a wide literature base which documents the benefits of outdoor learning on children's development (e.g. Waite and Davis 2007; Knight 2009; Storli and Hagen 2010; Eloquin and Hutchinson 2011; Tovey and Waller 2014). However, it is important to problematize the stereotypical, homogenous assumptions that some practitioners hold about who has most to gain from outdoor learning and assessment. For instance, many studies have demonstrated how gendered expectations are deeply embedded within school cultures, with teachers introducing stereotypes and bias through the language they use, the resources they draw upon, the subjects they encourage pupils to study and the way they interact with girls and boys (e.g. Soylemez 2010; Thompson 2011). Over-claims about gendered learning patterns have gained currency among teachers (MarksWoolfson 2011; Thompson 2011), resulting in assumptions such as 'boys require kinaesthetic learning styles' and 'girls preference for reading and writing' becoming part of contemporary educational discourse (Hamilton and Roberts 2015). Such statements, made without any acknowledgement, could further exacerbate gender stereotypes. As the comment below highlights, treating boys and girls as though they are homogenous groups is problematic as the differences within gender categories may be greater than those between them (Sundaram, 2010). Hamilton and Jones (2014) found how some boys, aged 6-7 years, described how playing outside was the worst thing about going to school.

Some people think boys benefit the most but it can also be girls. One girl in Year One loves it. She does much better outside than inside. (Teacher 3 )

Similarly assumptions should not be made that the outdoor classroom will always be favourable for children with additional learning needs.

One boy with Attention Deficit Hyperactivity Disorder can't cope and follow instructions at all when outside. He often comes in crying. (Teacher 4)

Bradbury (2014) asserts that practitioners frequently hold low expectations of certain groups of learners, such as those with special educational needs or from socio-economically deprived areas, which may lead them into thinking the outdoors is less academically challenging and hence more suitable for these children than the indoor classroom. This may result in practitioners sending certain children outdoors to 'let off steam' or to 'learn less academic aspects of the curriculum' as opposed to recognising the rich opportunities, that with the appropriate planning, can be offered to all children.

\section{Assessment: what, where, who, when?}

33 practitioners who completed the questionnaire said they could provide learning opportunities for all seven areas of learning within the Foundation Phase in the outdoor classroom. During the interviews there was also a feeling that, with adequate planning, most areas of learning could be covered effectively in the outdoor classroom. The role of the outdoor environment, however, seemed to be viewed by many in terms of what it could offer to enhance the teaching that occurs first in the indoor classroom, with no practitioners identifying new topics being introduced to children in the outdoors.

We have resources outside for all seven areas of learning on a daily basis. Numeracy and literacy can be done outdoors in a more meaningful way. Opportunities for knowledge and understanding of the world are vast. (Head Teacher)

You get a lot covered; literacy, numeracy, personal and social. With creativity the only way of seeing something in its true light is to take it outside. (Teacher 2)

You see skills developing which you may not see indoors. Sometimes it's easier to see team work skills outdoors. (Deputy Head Teacher) 
As can be seen from Figure 1, areas of learning that practitioners felt were more difficult to assess in the outdoor classroom included: creative development $(n 6)$, Welsh language development $(\mathrm{n} 4)$ and language, literacy and communication skills $(n$ 4). It seems that this was also the case in 2011 when Estyn reported how many schools failed to fully utilise the outdoor classroom to develop and assess children's skills in ICT; Welsh language; creativity; reading and writing.

Figure 1: How often areas of learning are assessed in the outdoors

During the interviews, practitioners discussed how the expense of ICT equipment and a lack of appropriate resources made it challenging to assess these areas of learning in the outdoors.

There's such a big push to teach using ICT but you're loathe to let the children take IPads outside because they are so expensive. (Teacher 3)

It is difficult finding resources for literacy that are suitable to use outdoors when assessing children. (Teacher 1)

The lack of appropriate resources means assessments for Welsh are usually done indoors. (Head Teacher)

However, the practitioners who were interviewed believed it was possible to assess these areas of learning; it just required more thought as to which strategies and resources to use. Interestingly, Maynard and Waters (2007) assert that many practitioners regulate the outdoor environment with distinctive areas for learning and replicate indoor activities outdoors, rather than utilising the natural resources available to them. It seems therefore, that the rich array of natural resources available to practitioners to support these areas of learning risk going unacknowledged, highlighting the importance that learning and assessing in the outdoor classroom becomes an integral part of continued professional development for teachers and initial teacher education courses.

Results from the questionnaire suggest practitioners rarely carry out assessments of children's learning in the outdoors, which supports the findings of Estyn (2011). Of the 37 participants, 24 claimed assessment was carried out equally in the indoor and outdoor environment, 12 stated that most assessment occurred in the indoors and 1 said it mainly took place in the outdoors. However, most practitioners commented that it was mainly formative assessment which took place in the outdoor classroom. Could the increasing pressure to promote children's literacy and numeracy skills, the requirements of the LNF (DfES 2013), cause practitioners to feel they need to carry out summative testing more in the indoor classroom as opposed to the outdoor classroom due to perceptions that it can be done more effectively inside? There appeared to be a correlation between the value practitioners placed on the outdoor environment and where they carried out their assessments. For example, the 5 practitioners who said that the outdoor environment had only 'some value', stated the majority of their assessments were undertaken inside the classroom. When asked how the assessment of children's learning was carried out, practitioners identified a range of methods.

Figure 2: Assessment methods used in the outdoor classroom

Only 4 out of the 37 practitioners identified summative testing as a method used in the outdoor classroom. Although due to the limited number of schools involved in the study no definite conclusions can be made, it is worth noting that the 4 practitioners who carried out summative assessments outdoors, worked in the two schools located in a socio-economically disadvantaged area. As discussed earlier, this could be the result of practitioners believing that the development of children facing social deprivation or those with additional learning needs are better served from the use of the outdoor environment.

As to whether it is teachers or teaching assistants who spend more time with children in the outdoor classroom, this appeared to be determined by the age of the child and perceived importance of the area of learning being supported and/or assessed. As can be seen from the comments below, teachers tend to carry out summative assessments of 'higher status' learning areas, such as maths and literacy, 
and work with older children, whilst teaching assistants usually work with younger children and support general observations (formative assessment) of 'softer' subject areas of the curriculum.

If it is the planting area, it's usually teaching assistants but if it is science or year two children, it will be a teacher. (Teacher 1)

Formal assessment, tends to be done by the teacher, and is classroom based. We do general observations and feedback to the teacher. (Teaching Assistant 3)

Teaching assistants spend most time outside because we do more of the supportive role rather than the formal work such as maths and literacy. (Teaching Assistant 4)

Children and parents may interpret the division of roles in the outdoor environment as meaning that certain areas of the curriculum are not valued as much as others or that the absence of the teacher from the outdoors signifies that more important learning takes place indoors. As will be discussed in the theme which follows, those least likely to have had training relating to the outdoor classroom are teaching assistants. This is of concern as it appears that teaching assistants are likely to spend more time with children in the outdoors supporting their holistic development; without appropriate training they may not fully support children's learning and assessment opportunities.

\section{Factors hindering outdoor assessment}

When practitioners were asked which factors made assessing learning in the outdoor environment successful, the following were regarded as being most significant: level of child's confidence and independence; effective planning; knowledgeable and supportive adult and; appropriate outdoor resources.

Figure 3: Key factors for effective assessment in the outdoors

When asked what made it difficult to assess children in the outdoors, practitioners identified: staff attitude and expertise; quality of appropriate resources; the degree of risk involved; adverse weather; staffing ratios; and changes to curriculum policy which emphasise the formal assessment of children.

Although all practitioners involved in the study valued outdoor learning it might be that some, as Fägerstam and Samuelsson (2014) identified, undervalue the role that the outdoor environment can have in enabling children to reach higher levels of cognitive understanding and for summative assessment. This highlights the importance of offering specialised training for practitioners in this area. Although 29 of the 37 practitioners claimed they had received training related to the outdoor classroom, consideration needs to be given to the quality and content of the training opportunities undertaken. It should also be noted that of the 8 practitioners who had received 'no training' in the use of the outdoor environment, all were teaching assistants. In 2011, Estyn (2011) identified how there were inadequate training opportunities for practitioners and senior managers, which led to less effective outdoor learning environments and assessment opportunities. Only 3 practitioners involved in this current study regarded the training that they had received to be 'effective' or 'valuable'. Most practitioners referred to one type of training only, including: Creative Learning Outdoors; Woodland Trust; Forest School; Flying Start; Using the Outdoors; Foundation Phase; training which had been provided by their local education authority, partnership groups, or observations undertaken when visiting other settings.

As previously highlighted, many practitioners discussed how certain areas of learning lacked appropriate resources for outdoor learning and assessment which prevented or made it difficult to cover ICT; creative development; Welsh language; and language, literacy and communication skills. However, in one setting, where a resource specific to utilising the outdoors had been purchased, it was regarded as an 'excellent tool' for both facilitating children's learning and supporting practitioners with assessment across all areas of the curriculum, leading to an enhancement of practice.

Contrary to the literature base, which presents factors making practitioners reticent to provide outdoor learning experiences, in the fear of health and safety litigation (Bundy et al. 2009), the level of children's competence (Waller et al. 2010) and self-confidence in use of the outdoors (Knight 2011), 
practitioners in this study, despite referring to hazards, discussed how a degree of risk-taking provided by the outdoors was fundamental in helping children to develop essential life and problem solving skills.

Children need to take risks to be risk aware. It's about teaching children to manage risks and staff knowing when to step back and when to step in. (Head Teacher)

Features that were identified as a potential risk were mostly natural hazards, such as slippery surfaces, falling from heights (tress and play equipment), plants, insects and animals. One practitioner discussed how a lack of space resulted in restrictions being placed on how many children could go outside at any one time due to safety precautions. Another practitioner, highlighted below, illustrated how inadequate staff-child ratios, due to the additional needs of some children, might lead to a reduced utilisation of the outdoor environment.

We used to have an open door policy for children to go in or out all of the time but now we are not able to. We have one member of staff to every 5 children but $70 \%$ of our children have additional needs. So many are in nappies it means two members of staff are continually changing nappies instead of interacting with the children outside. (Head Teacher)

However, in general, the risks associated with the outdoors were deemed not to be much greater than the risks children might be exposed to when indoors.

The risks are similar to those indoors. Before we start every day, we make sure the resources are safe. Inside we sand down the wooden blocks to avoid splinters. Outside we remove litter left by people and animals. (Deputy Head Teacher).

15 practitioners identified weather, in particular rain, as being a factor which prevented them from carrying out outdoor assessments. Some practitioners discussed how some children did not like to wear outdoor clothing to protect them from the rain while other children when wet wanted to return to the indoor classroom. The weather is regularly identified within the extant literature as being one of the main issues practitioners have when using the outdoor classroom (Maynard and Waters 2007; Sime and Taplin 2011). Although this can be overcome by providing appropriate clothing/resources (Knight 2011), going out in inclement weather may remain an issue due to the child's or practitioner's personal or cultural traits. However, as Klaar and Öhman (2014) contend, with access to regular opportunities and resources, venturing out in the rain may become an internalised habit.

All 10 practitioners interviewed believed the Foundation Phase, with its emphasis on outdoor learning, to be an effective curriculum that supported children's holistic development and well-being. However, some were concerned that recent changes to the curriculum, due to the increased pressure to prepare children for Key Stage Two, was making education too narrow and assessment driven, which they feared might have a detrimental impact on the philosophy of the Foundation Phase and use of the outdoor classroom.

The Foundation Phase helps children to shine but government policies are putting more pressure on making us get children ready for Key Stage 2. Outdoor learning now depends on how much value it is given by the head teacher. (Teacher 1)

Things are becoming so data driven, so prescribed, you have to do them inside because you need to have proper evidence. You're losing the outdoors because of this pressure. (Teacher 3)

The Literacy and Numeracy Framework is going back to a formal style of learning. I can teach children to follow tests or I can teach them the Foundation Phase, life and thinking skills. Some teachers don't follow the Foundation Phase anymore because they have to pass tests. It's like going back to Standard Assessment Tests. (Teacher 4)

These statements illustrate the conflict and dilemma some practitioners may experience when a shift in educational philosophy leads to curriculum changes and demands which are in opposition to their own beliefs and practices. The rich experiences afforded to children through outdoor learning, emphasised in curriculum documents such as the Foundation Phase, have been promoted for over a decade (Tovey 
and Waller 2014). Thus, policy-drivers reverting back to a more traditional format of education may be difficult for some practitioners and settings to adjust to. Although, discussing proposals to be made to the Welsh curriculum, a result of the Donaldson Report (2015), one practitioner was hopeful that there would remain an emphasis on supporting young children's holistic development and learning through the use of the outdoor environment.

The Donaldson Report is all about holistic education and that's what we're about here. The outdoors supports this. It offers a richer experience than just using the indoors. (Deputy Head Teacher)

However, with the key focus set on raising children's attainment in English, maths, science and ICT, the impact that this will have on the use of the outdoor classroom remains to be seen.

\section{Conclusion}

Assessing children in the outdoor environment is clearly valued by practitioners, with use of the outdoors considered to be fundamental to the holistic development of young children. Some practitioners believed assessing children in the outdoors was similar to assessing in the indoors but that it could further identify aspects of development that might not be fully acknowledged through use of the indoor classroom alone. Fewer constraints associated with the outdoor classroom, practitioners claimed, meant that children were not always aware that they were being questioned about their learning, so they responded more freely.

It seems that all seven areas of learning within the Foundation Phase, including the LNF, can be covered and assessed in the outdoors. However, there was consensus that the outdoor classroom was not always used to its potential to support children's learning and that Welsh language; language and literacy; creative development; and ICT were difficult to address and assess in the outdoors. Challenges included: adverse weather; lack of appropriate resources; level of staff expertise; changes to curriculum policy; insufficient child-staff ratio, particularly where children have specific physical needs. Although ensuring children's safety was highlighted, there was a belief that the element of risk involved in outdoor learning was essential, as it helps children to develop essential life skills.

One of the main concerns practitioners had was that current policy-drivers, at odds with the philosophy of the Foundation Phase, risk impacting on the amount of time allocated to outdoor learning and assessment. The increasing pressure to formally test children's literacy and numeracy, could explain why the outdoor environment may tend to be utilised as a secondary resource, in terms of supporting the teaching and assessment that occurs in the indoor classroom. The increased accountability that testing brings about for teachers and the need to generate evidence of children's learning is likely to govern who undertakes assessments and where these are carried out. The study shows how teachers typically carried out summative assessments of children inside the classroom, while teaching assistants were more involved in formative assessments in the outdoors. The comment made by Teacher 3 "Things are becoming so data driven, so prescribed, you have to do them inside because you need to have proper evidence" may suggest that learning outdoors is not perceived to be as valuable, or assessment as reliable or as easy to evidence, as compared to that undertaken within the indoor classroom. This could be reflective of the limited training available to practitioners, resulting in a lack of confidence of the unique and wide range of opportunities that the outdoor classroom can provide to children's learning and assessment.

There was a perception that outdoor learning and assessment was more beneficial to some children than others (i.e. boys; children in socio-economically deprived areas; children with language difficulties or delayed social development). Care must be taken that stereotypical views do not result in homogenous assumptions, which narrow experiences for learners; in particular lowering expectations and using the outdoors for children 'less able to cope' with 'higher status subjects' and the more 'formal teaching methods' associated with the indoor classroom. An area which warrants further research is the amount of time children spend learning and being assessed outdoors on the basis of socio-economic factors. Do settings in socially deprived areas give children more access and undertake more formal assessments in the outdoors as compared to settings located in socio-economically advantaged areas?

To enhance policy and practice relating to learning and assessing in the outdoor environment this study offers the following recommendations i) broad training opportunities, which go beyond one type of training course, and consider planning and assessing in the outdoor classroom, should be an 
integral part of continued professional development for all early years practitioners, and for those on initial teacher education and vocational childcare courses ii) resources specific to learning and assessing in the outdoors need to be made available to settings; iii) all early years settings should be provided with adequate outdoor classroom space.

This paper has aimed to encourage practitioners to maximise critical reflection about the use of the outdoor environment and the need to promote inclusive and personalised learning and assessment opportunities. There is an urgent need for practitioners to become more reflexively aware of how to balance the pressure of formally testing children so that the rich opportunities afforded by the outdoor classroom for assessing children's holistic development are not impeded. With more creative thought during planning, and the use of specific resources, there is no reason why summative assessments of all areas of learning within the early years' curriculum, including the LNF, cannot be done as effectively outdoors as they are hopefully being done indoors.

\section{References}

Aasen, W., Grindheim, L. T. and Waters, J. (2009), 'The outdoor environment as a site for children's participation, meaning-making and democratic learning: Examples from Norwegian kindergartens', Education 3 - 13: International Journal of Primary, Elementary and Early Years Education, Vol. 37, No. 1, pp. 5 - 13.

Allsopp, N. (2014), 'Assessment', in Curtis, W., Ward, S., Sharp, J. and Hankin, L. (eds), Education Studies: An Issue Based Approach. Third Edition. pp. 61-74. London: Sage.

Bartlett, S. and Burton, D. (2016), 'The influence of gender in the classroom: how boys and girls learn', in Richards, G. and Armstrong, F. (eds), Teaching and Learning in Diverse and Inclusive Classrooms. Second Edition. pp. 54-64. Oxon: Routledge.

Basford, J. and Bath, C. (2014), 'Playing the assessment game: An English early childhood education perspective', Early Years, Vol. 34, No. 2, pp. 119 - 132.

Bradbury, A. (2014), 'Learning, assessment and equality in Early Childhood Education (ECE) settings in England', European Early Childhood Education Research Journal, Vol. 22, No. 3, pp. $347-354$.

Bundy, A. B., Luckett, T., Tranter, P. J., Naughton, G. A., Wyver, S. R., Ragen, J. and Spies, G. (2009), 'The risk is that there is 'no risk': A simple, innovative intervention to increase children's activity levels', International Journal of Early Years Education, Vol. 17, No. 1, pp. $33-45$.

Denscombe, M. (2010), The Good Research Guide For Small Scale Social Research Projects. Fourth Edition. Maidenhead: Open University Press.

Department for Children, Education, Lifelong Learning and Skills [DCELLS] (2008), Foundation Phase Framework for Children's Learning for 3 to 7-year-olds in Wales. Cardiff: Welsh Assembly Government.

Department for Children, Education, Lifelong Learning and Skills [DCELLS] (2009), Foundation Phase Outdoor Learning Handbook. Cardiff: Welsh Assembly Government.

Department for Education and Skills [DfES] (2013), National Literacy and Numeracy Framework: To Support Schools in Introducing the National Literacy and Numeracy Framework. Information Document. Cardiff: Welsh Government.

Department for Education and Skills [DfES] (2014), Curriculum for Wales: Revised Areas of Learning (Language, Literacy and Communication Skills and Mathematical Development) and Programmes of Study (English, Welsh (First Language) and Mathematics) - Foundation Phase to Key Stage 4. Phase 1: Literacy and Numeracy. Consultation - Summary of Responses. Cardiff: Welsh Government.

Donaldson, G. (2015), Successful Futures: Independent Review of Curriculum and Assessment Arrangements in Wales. Cardiff: Welsh Government.

Elliott, H. (2014), 'Forest School in an inner city? Making the impossible possible', Education 3-13: International Journal of Primary, Elementary and Early Years Education, Vol. 42, No. 2, pp. $1-9$.

Eloquin, X. and Hutchinson, T. (2011), 'SEALs in the Woods', in Knight, S. (ed.), Forest School for All, pp. 137 - 152. London: Sage Publications Limited.

Fägerstam, E. and Samuelsson, J. (2014), 'Learning arithmetic outdoors in junior high school - 
influence on performance and self-regulating skills', Education 3 - 13: International Journal of Primary, Elementary and Early Years Education, Vol. 42, No. 4, pp. 419 - 431.

Glazzard, J. (2014), 'Observation and assessment', in Mukherji, P. and Dryden, L. (eds), Foundations of Early Childhood. Principles and Practice. pp. 62-80. London: Sage.

Groves, L. and McNish, H. (2011), Natural Play: Making a Difference to Children's Learning and Wellbeing: A Longitudinal Study of the Forestry Commission - Merrylee Primary School Glasgow City Council Partnership 2008 - 2011.Executive Summary. Edinburgh: Forestry Commission Scotland.

Hamilton, P. and Jones, L. (2014), 'Illuminating the 'boy problem' from children's and teachers' perspectives: a pilot study', Education 3-13: International Journal of Primary, Elementary and Early Years Education, published on-line: 08 April 2014, DOI: 10.1080/03004279.2014.903987

Hamilton, P. and Roberts, B. (2015), 'Man-up, go and get an ice-pack. Gendered stereotypes and binaries within the primary classroom: a thing of the past?' Education 3-13: International Journal of Primary, Elementary and Early Years Education, published on-30 June 20152015, DOI: 10.1080/03004279.2015.1059871

Hännikäinen, M. and Rasku-Puttonen, H. (2010), 'Promoting children's participation: The role of teachers in preschool and primary school learning sessions', Early Years, Vol. 30, No. 2, pp. $147-160$.

Her Majesty's Inspectorate for Education and Training in Wales [Estyn] (2011), Outdoor Learning, an Evaluation of Learning in the Outdoors for Children Under Five in the Foundation Phase. Crown Copyright. Cardiff: Estyn Publication Section.

Humberstone, B. and Stan, I. (2011), 'Outdoor learning: Primary pupils' experiences and teachers' interaction in outdoor learning', Education 3 - 13: International Journal of Primary, Elementary and Early Years Education, Vol. 39, No. 5, pp. 529 - 540.

Johnson, T. (2014), 'Recent legislation and policy initiatives (1997-present)', in Mukherji, P. and Dryden, L. (eds), Foundations of Early Childhood. Principles and Practice. Pp. 202-222. London: Sage.

Klaar, S. and Öhman, J. (2014), 'Children's meaning-making of nature in an outdoor-oriented and democratic Swedish preschool practice', European Early Childhood Education Research Journal, Vol. 22, No. 2, pp. $229-253$.

Knight, S. (2009), Forest Schools and Outdoor Learning in the Early Years. London: Sage Publications Limited.

Knight, S. (2011), Risk and Adventure in Early Years Outdoor Play: Learning from Forest Schools. London: Sage Publications Limited.

Learning and Teaching Scotland (2010), Curriculum for Excellence through Outdoor Learning. Glasgow: Learning and Teaching Scotland.

Lee-Hammond, L. and Waller (2014), 'International perspectives', in Waller, T. and Davis, G. (eds), An Introduction to Early Childhood. Third Edition. pp. 27-46. London: Sage.

Little, H., Wyver, S. and Gibson, F. (2011), 'The influence of play context and adult attitudes on young children's physical risk-taking during outdoor play', European Early Childhood Education Research Journal, Vol. 19, No. 1, pp. 113 - 131.

Marks-Woolfson, L. (2011), Educational Psychology. The Impact of Psychological Research on Education. Essex: Pearson

May, P., Ashford, E. and Bottle, G. (2006), Sound Beginnings: Learning and Development in the Early Years. London: David Fulton Publishers.

Maynard, T. and Chicken, S. (2010), 'Through a different lens: Exploring Reggio Emilia in a Welsh context', Early Years: An International Journal of Research and Development, Vol. 27, No. 3, pp. 255-265.

Maynard, T. and Waters, J. (2007), 'Learning in the outdoor environment: A missed opportunity', Early Years: An International Journal of Research and Development, Vol. 27, No. 3, pp. 255265.

McInnes, K., Howard, J., Crowley, K. and Miles, G. (2013), 'The nature of adult-child interaction in the early years classroom: Implications for children's perceptions of play and subsequent learning behaviour', Early Years: An International Journal of Research and Development, 
Vol. 21, No. 2, pp. 268-282.

Muijs, D. and Reynolds, D. (2011), Effective Teaching. Evidence and Practice. Third Edition.

London: Sage.

O’Brien, L. (2009), 'Learning outdoors: The Forest School approach', Education 3 - 13, Vol. 37, No. 1, pp. $45-60$.

O’Brien, L. and Murray, R. (2006), A Marvellous Opportunity for Children to Learn: A Participatory Evaluation of Forest School in England and Wales. Farnham: Forest Research.

Organisation for Economic Co-operation and Development [OECD] (2014), Improving Schools in Wales: An OECD Perspective. Paris: OECD.

Sime, E. and Taplin, L. (2011), 'Physical development, health and well-being: The role of physical education 'outside', in Waite, S. (ed.), Children Learning Outside the Classroom: From Birth to Eleven, pp. 133 - 146. London: Sage Publications Limited.

Siraj-Blatchford, I., Sylva, K., Laugharne, J., Milton, E. and Charles, F. (2006), Foundation Phase Pilot: First Year Evaluation Report. Monitoring and Evaluation of the Effective Implementation of the Foundation Phase (MEEIFP) Project Across Wales. Cardiff: Department for Training and Education.

Soylemez, A. (2010), 'A study on how social gender identity is constructed in EFL coursebooks', Procedia Social and Behavioral Sciences, Vol. 9, No. 1, pp. 747-752.

Storli, R. and Hagen, T. L. (2010), 'Affordances in outdoor environments and children's physically active play in pre-school', European Early Childhood Education Research Journal, Vol. 18, No. 4 , pp. $445-456$.

Sundaram, V. (2010), 'Gender and education', in Arthur, J. and Davies, I. (eds), Education Studies Textbook, pp. 50-60. Oxon: Routledge

Thompson, B. (2011), 'Reassessing gender issues in the primary classroom', in Knowles, G. (ed), Supporting Inclusive Practice. Second edition. pp. 46-62. Oxon: Routledge.

Tickell, C. (2011), The Early Years: Foundations for Life, Health and Learning. An Independent Report on the Early Years Foundation Stage Framework to Her Majesty's Government. London: DfE.

Tovey, H. and Waller, T. (2014), 'Outdoor play and learning', in Waller, T. and Davis, G. (eds), An Introduction to Early Childhood. Third Edition. pp.146-165. London: Sage.

Waite, S. (2011), 'Making a difference: Learning on a grand scale', in Waite, S. (ed.), Children Learning Outside the Classroom: From Birth to Eleven, pp. 201 - 212. London: Sage Publications Limited.

Waite, S. and Davis, B. (2007), 'The contribution of free play and structured activities in Forest School to learning beyond cognition: An English case', in Ravn, B. and Kryger, N. (eds), Learning Beyond Cognition, pp. 257 - 274. Copenhagen: The Danish University of Education.

Waite, S. and Pratt, N. (2011), 'Theoretical perspectives on learning outside the classroom: Relationships between learning and place', in Waite, S. (ed.), Children Learning Outside the Classroom: From Birth to Eleven, pp. 1 - 18. London: Sage Publications Limited.

Waldron, S., Rhys, M. and Taylor, C. (2014a), Evaluating the Foundation Phase: Key Findings on Children and Families. Cardiff: Welsh Government Social Research.

Waldron, S., Rhys, M. and Taylor, C. (2014b), Evaluating the Foundation Phase: Key Findings on Pedagogy and Understanding. Cardiff: Welsh Government Social Research.

Waller, T., Sandseter, E. B. H., Wyver, S., Ärlemalm-Hagsér, E. and Maynard, T. (2010), 'The dynamics of early childhood spaces: Opportunities for outdoor play?', European Early Childhood Education Research Journal, Vol. 18, No. 4, pp. 437 - 443.

Waters, J. (2013), 'Talking in wild outdoor spaces: Children bringing their interests to their teachers in Wales', in Knight, S. (ed.), International Perspectives on Forest School: Natural Spaces to Play and Learn, pp. 12 - 26. London: Sage Publications Limited.

Wragg, M. (2013), 'Towards an inversion of the deficit model of intervention in children's play', European Early Childhood Education Research Journal, Vol. 21, No. 2, pp. 283 - 291. 